\title{
VERPASSTE CHANCE
}

\section{Liebe Leserin, lieber Leser,}

es ist Fakt, dass an der Elektrifizierung des Antriebs kein Weg vorbeiführt. Ebenso Common Sense ist, dass neben der Hybridisierung auch reine E-Antriebe für bestimmte Fahrprofile eine zukunftsweisende Lösung sind. Die Industrie hat entwicklungstechnisch ihre Hausaufgaben gemacht und leistungsfähige Antriebe entwickelt, die bereits im Markt sind oder kurz vor der Markteinführung stehen. So weit - so gut. Aber stimmen die Rahmenbedingungen, die für eine nachhaltige Marktdurchdringung vonnöten sind?

Zumindest bei den Hybridantrieben scheint klar zu sein, dass diese in wenigen Jahren einen relevanten Anteil bei den Fahrzeugantrieben stellen werden. Wie aber ist die Situation bei den reinen E-Antrieben? In Ländern wie etwa China, Frankreich, den USA, Großbritannien oder den Niederlanden erhalten Kunden Steuervorteile von teilweise über 6000 Euro beim Kauf eines Fahrzeugs mit E-Antrieb, um so den Stromern zum Durchbruch zu verhelfen. Im Geburtsland des Autos hingegen gibt es dagegen so gut wie keine Absatzförderung für alternative Antriebe. Wie so eine rasche Verbreitung von Elektroautos zur Senkung des $\mathrm{CO}_{2}$ Ausstoßes beitragen soll, bleibt ein Rätsel. Die propagierte Zahl von einer Million Fahrzeugen bis 2020 gehört damit in das Reich der Märchen und Fabeln.

$\mathrm{Zu}$ einer gezielten und strategischen Markteinführung von sauberen Elektrofahrzeugen ist es ebenso notwendig, auch „sauberen“ Strom aus regenerativen Quellen gezielt zu fördern und zur Verfügung zu stellen. Aber auch dies geschieht hierzulande nicht in dem Maße, das für eine zügige Entwicklung notwendig wäre. Im Gegenteil: Die jüngst erfolgten Kürzungen auf diesem Gebiet führen die hehren Pläne der Bundesregierung ad absurdum und zementieren mehr oder weniger den Anteil fossiler Energieträger. Konkret bedeutet dies, dass je nach Strommix ein Elektroauto auch in Zukunft noch bis $\mathrm{zu} 128 \mathrm{~g} \mathrm{CO}_{2}$ pro Kilometer ausstoßen kann - nämlich dann, wenn der hierfür „gezapfte“ Strom beispielsweise auch aus Braunkohle erzeugt wurde. Ein Kompaktwagen mit modernem aufgeladenem Verbrennungsmotor ist da deutlich $\mathrm{CO}_{2}$-neutraler unterwegs und dabei noch wesentlich günstiger!

Das ist strategisch alles andere als sinnvoll, und die Exekutive hat hier ihre Chance zur Zukunftsentwicklung nicht genutzt. Da bleibt eigentlich nur eines: die gezielte Weiterentwicklung des klassischen Verbrennungsmotors. Dieser hat - ob Benzin oder Diesel - noch viel Potenzial und wird auch die kommenden 20 Jahre noch den Hauptanteil der Fahrzeugantriebe stellen. Freuen wir uns drauf!

Herzlichst, Ihr

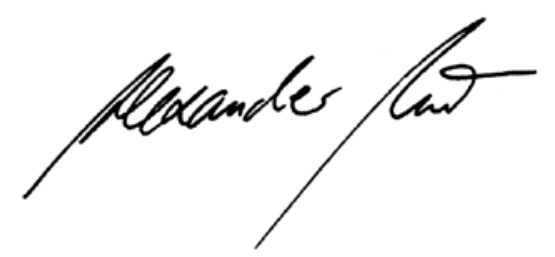

DR. ALEXANDER HEINTZEL, Chefredakteur Wiesbaden, 21. März 2013

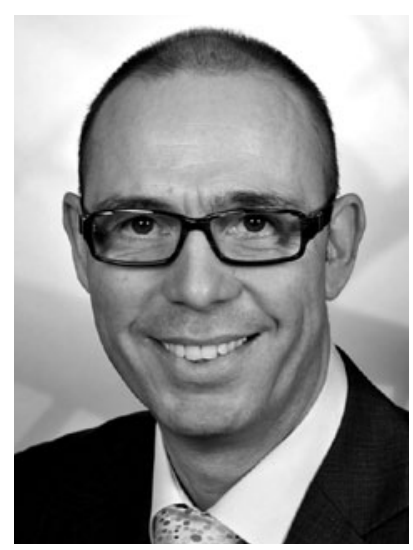

DYNA4 Advanced Powertrain

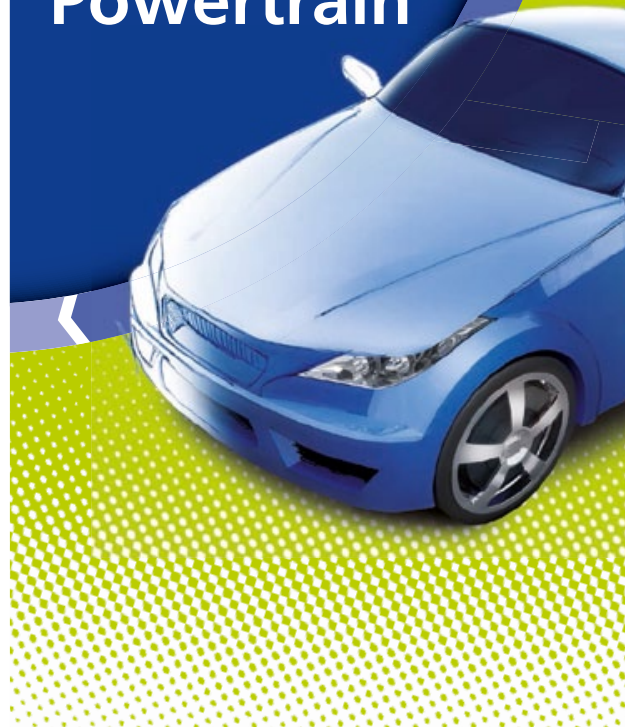

\section{Energiemanagement im Fahrzeug}

- Simulation von Einzelfahrzeugen bis hin zur Fahrzeugflotte

- Fahrleistungs- und Verbrauchsberechnungen

- Konventionelle Antriebe, Hybridund Elektrofahrzeuge

- Variantenhandling, Automation und Reporting

Mehr erfahren unter www.tesis-dynaware.com/flv 